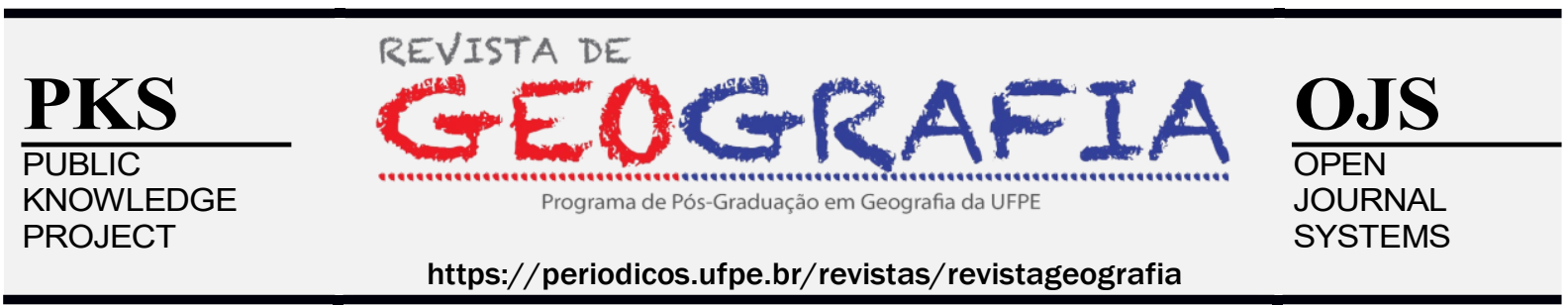

\title{
AS DUAS FORMAS DE SABERES: DA ETIMOLOGIA AOS SIGNIFICADOS DE VERNACULAR E VEICULAR EM GEOGRAFIA
}

\author{
José Wellington Lúcio Soares ${ }^{1}$, Raimundo Freitas Aragão² \\ ${ }^{1}$ Universidade Estadual do Ceará (UECE). Licenciado em Geografia. Especialista em Educação. Mestre em \\ Geografia. Doutor em Geografia. E-mail: zezinflauta@hotmail.com; http://orcid.org/0000-0002-0079-5857 \\ ${ }^{2}$ Universidade Federal do Ceará (UFC). Mestre e Pós-Doutor em Geografia pela Universidade Federal do \\ Ceará. Licenciado em Filosofia e Bacharel em Geografia. Especialista em educação Ambiental. E-mail: \\ ararageo2007@yahoo.com.br; http://orcid.org/0000-0002-3428-0712
}

Artigo recebido em 03/10/2019 e aceito em 11/03/2021

\begin{abstract}
RESUMO
Propõe-se neste artigo apresentar duas formas complementares de saberes ainda poucos debatidos na Geografia acadêmica brasileira, quais sejam: o saber vernacular e o saber veicular. $O$ primeiro referente ao saber popular e o segundo ao saber científico. A base do procedimento metodológico é o de pesquisa bibliográfica com o suporte de diferentes trabalhos científicos pluridisciplinares, ou seja, utiliza-se não só autores geógrafos. Tais trabalhos são utilizados como ferramentas básicas de estudos monográficos considerados essenciais quando se busca o domínio sobre determinado tema. Espera-se que o artigo contribua para a ampliação do conhecimento no que toca aos saberes que envolvem o mundo da pesquisa acadêmica geográfica.
\end{abstract}

Palavras-chave: Vernacular; Veicular; Geografia; Paisagem; Patrimônio.

\section{TWO WAYS OF KNOWLEDGE: FROM ETYMOLOGY TO THE MEANINGS OF VERNACULAR AND VEHICULAR IN GEOGRAPHY}

\begin{abstract}
It is proposed in this article to present two complementary forms of knowledge that are still little debated in Brazilian academic geography, namely: vernacular knowledge and vehicular knowledge. The first refers to traditional beliefs and, the second to scientific knowledge. The methodological procedure is that of bibliographical research with the support of different multidisciplinary scientific works, not only geographical authors used. Such works are basics tools for monographic studies considered essential when seeking mastery over a particular topic. Hopefully, it's expected that the article will contribute to a better opening in the spread of knowledge regarding the knowledge that involves the world of geographic research.
\end{abstract}

Key-words: Vernacular; Vehicular; Geography; Landscape; Heritage. 


\title{
LES DEUX FAÇONS DE SAVOIR: DE L'ÉTYMOLOGIE AUX SIGNIFICATIONS DU VERNACULAIRE ET DU VÉHICULAIRE EN GÉOGRAPHIE.
}

\begin{abstract}
RÉSUMÉ
Il est proposé dans cet article de présenter deux formes de savoirs complémentaires encore peu débattues en géographie académique brésilienne, à savoir: les savoirs vernaculaires et les savoirs véhiculaires. Le premier renvoie aux savoirs traditionnelles et le second aux connaissances scientifiques. La démarche méthodologique est celle d'une recherche bibliographique avec l'appui de différents travaux scientifiques pluridisciplinaires et non seulement les auteurs géographiques sont utilisés. Tels travaux sont des outils de base pour des études monographiques considérées comme essentielles lorsqu'on cherche à maîtriser un sujet particulier. On s'attend à ce que l'article contribuera à une meilleure ouverture dans la diffusion des connaissances concernant les connaissances qui impliquent le monde de la recherche géographique.
\end{abstract}

Mots-clés: Vernaculair; Véhiculair; Géographie; Paysage; Patrimoine.

\section{INTRODUÇÃO}

Este artigo tem como objetivo central o de apresentar os termos "vernacular" e "veicular" não comuns no âmbito do ensino acadêmico geográfico brasileiro. A ideia surgiu a partir das pesquisas realizadas pelo professor geógrafo da Universidade Estadual do Ceará UECE, Dr. Otávio José Lemos Costa que, desde 2001, o qual vem trabalhando como pesquisador e orientador sobre os temas patrimônio e paisagem, concentrando-se sobre o "patrimônio vernacular" do Sertão cearense a exemplos das regiões de Icó, localizado na mesorregião do Centro-Sul do estado e do maciço residual da Serra da Meruoca, na porção Noroeste do Ceará.

A partir do levantamento bibliográfico e leitura sobre vernacular surgiu a sua imagem complementar, o veicular. Por isso, da curiosidade sobre o vernacular ou conhecimento comum fez-se necessário remeter sobre o termo veicular, ligado ao mundo acadêmico. Questionou-se, então: o que é verdadeiramente vernacular, qual sua origem? Como evoluiu e como a Geografia dele se apropria? E o seu complemento, quais relações mantém com o vernacular? São estas as questões a serem respondidas neste artigo.

O procedimento metodológico é a pesquisa bibliográfica e tem como suporte obras que versam diretamente sobre o objeto de estudo. Tais obras são utilizadas como ferramentas de procedimentos básicos de estudo monográficos, considerados essenciais no domínio de 
determinado tema. Dessa forma, os conhecimentos geográficos "vernacular" e "veicular" são parcialmente dissecados. Os autores, todos de linhagem acadêmica, e não necessariamente geógrafos, são postos a refletirem e dialogarem sobre os termos.

$\mathrm{O}$ artigo está dividido em seis partes. A primeira trata-se desta introdução. A segunda traz, em primeira mão, as considerações do geógrafo francês Claude Raffestin, o qual pode ser considerado um dos primeiros a refletir sobre os termos em um artigo em Geografia. Na terceira, realiza-se o levantamento etimológico de vernacular, como e onde nasce e se diferencia ao longo da história. Na quarta, em artigo mais recente, a geógrafa francesa Béatrice Collignon $(2005 ; 2014)$ reflete sobre as características dos termos e presenteia a academia com sua própria concepção de vernacular e veicular. É o que também faz o geógrafo francês Jêróme Monnet (1999a; 1999b) na quinta parte. Ambos oferecem uma noção muito próxima, porém divergindo metodologicamente. A sexta parte são as considerações finais.

\section{O COMEÇO: A CAPTURA DOS TERMOS PELO GEÓGRAFO CLAUDE RAFFESTIN}

Os artigos intitulados "La langue comme ressource: pour une analyse économique des langues vernaculaires et vehiculaires" e "Langue et territoire. Autour de la géographie culturelle" do geógrafo francês Claude Raffestin (1978; 1995) utilizam os vocábulos vernacular e veicular e sua inserção em Geografia, diferenciando-os. Pode-se sugerir que Raffestin foi um dos pioneiros em trazer um estudioso da linguística para explicar um fenômeno e colocá-lo em um contexto geográfico ${ }^{1}$.

Nesses artigos, Raffestin (1978) traz a linguística de Henri Gobard de maneira formal, ou seja, para diferenciar os termos em suas funções, mesmo porque considera uma língua dominante não como fato linguístico propriamente, mas “[...] um problema social lato sensu que, para ser posto, necessita de mobilização de dados sobre relações políticas, econômicas, sociais e culturais. Em outros termos, é um problema de poder, de relações de poder e de estrutura de poder." (RAFFESTIN, 1978, p. 279). Portanto, para além de uma questão de linguística, a posição da língua, segundo ele, é também uma questão espacial e territorial. A

\footnotetext{
${ }^{1}$ Collignon (2005) aponta a "geografia do espaço vivido" desenvolvida por Armand Fremont, no ano de 1974, como germe sobre geografia vernacular. No entanto diz ela, ter se tratado senão de germe.
} 
língua, como diz, é um desafio, um recurso, pois está diretamente ligada à produção e ao consumo. Está ligada ao mesmo tempo a um processo e a uma atividade territorial.

\begin{abstract}
Língua e território estão presentes em todas as ações coletivas e individuais igualmente: é difícil imaginar situações nas quais língua e território não sejam parte interessada de uma maneira ou de outra, nas quais seus "mediadores" não tenham algum papel enquanto meios ou fins (RAFFESTI, 1995, p. 90).

Paradoxalmente, a origem da língua não é um problema linguístico e simetricamente a origem do território não é um problema geográfico. Em efeito, pode-se desconhecer a origem da língua e do território e ainda submeter essas duas produções a análises tanto precisas quanto esclarecedoras. Essa maneira de se desembaraçar do problema pode não ser elegante, mas é possível compensar essa relevância pelos recursos, justamente, no limite, pois sem delimitação não há nem língua e nem território. (RAFFESTIN, 1995, p. 94).
\end{abstract}

Para sustentar essa teoria de língua como poder no contexto territorial, ele apresenta as quatro funções da língua na reprodução social, apresentadas da seguinte forma levando em consideração a distinção de Henri Gobard: a primeira é a língua vernacular, a falada no local, ou seja, na casa, na rua, e espontaneamente para se comunicar; a segunda é a língua veicular, de alcance mais amplo, nacional ou regional, realizada pela necessidade; pode ser utilizada no lugar de trabalho e de estudo. Esse alcance abrange as comunicações na escala entre cidades; a terceira é a língua referência, esta ligada às tradições culturais, orais ou escritas, nas quais asseguram as continuidades dos valores para uma referência sistemática às obras do passado; a quarta, e última, é a língua mítica. Esta última funciona como último recurso, uma espécie de mágica verbal a qual compreende-se a incompreensibilidade como prova irrefutável do sagrado.

Ao refletir sobre o território do cotidiano locus onde se realiza a vida corrente, daquilo que é "evidente" (ce qui va de soi), retomando essa expressão de Henri Lefebvre na língua original, Raffestin (1995, p. 91) expõe a tradução de vernacular para o contexto da Geografia com o aporte da linguística.

A este território corresponde uma língua cotidiana ou língua vernacular. Esse vernacular pode ser um dialeto, uma língua falada por um pequeno número de indivíduos, ou simplesmente uma língua dividida no interior de uma grande língua de cultura como o inglês, o francês, o alemão, o espanhol ou o italiano. Esses vernaculares são geralmente os idiomas mais difíceis de compreender pelos estrangeiros, pois eles são relativamente pobres em palavras e relativamente ricos em expressões idiossincráticas em expressões cujo uso frequente, senão cotidiano, controla a situação. (RAFFESTIN 1995, p. 91). 
No entanto, para nós, interessam somente os significados de vernacular e veicular e suas relações em geografia. Dessa forma, para melhor aporte de entendimento, seria útil realizarmos previamente um levantamento etimológico do termo vernacular e seus significados em outra ciência, para depois nos debruçarmos sobre como a Geografia mais recentemente as tem tratado e, assim, observarmos suas aproximações e relações.

\section{AGORA, A NOSSA VIAGEM ETIMOLÓGICA NO TEMPO E NO ESPAÇO COM A AJUDA DA ARQUITETURA E DAS ARTES}

A pesquisa realizada por Marie-France Bisson (2007) intitulada "Vernaculaire moderne? Vers une compréhension de la notion d'architecture vernaculaire et des ses liens avec la modernité architecturale ${ }^{2}$, , defendida como exigência parcial de mestrado no estudo das Artes na Universidade de Quebec, em Montreal, será o nosso guia para esta parte, tanto pela riqueza de detalhes quanto pelo aprofundamento que faz do vasto e rico referencial bibliográfico que a autora utiliza em línguas francesa e inglesa. Seu trabalho direcionado ao estudo das artes procura estabelecer em que momento o vernacular, como adjetivo, passa a determinar uma construção física como um edifício ou prédio. Portanto, sai-se da Linguística das explicações e adentra-se na seara da Arquitetura.

Primeiro ela busca a origem do vernacular no latim. A palavra latina vernaculus é "relativa aos escravos nascidos em casa" a qual em seu sentido figurado quer dizer "que é do país, nativo". Dessa forma, a raiz latina verna vai inspirar a língua francesa com o termo vernade que, segundo ela, vai diferenciar o escravo nascido na casa de seu proprietário, isso nos idos de 1372. No século XVI, esse termo será substituído pelo termo adjetivado vernaculaire que determina uma língua local, familiar. Foi somente no século XVIII, ou seja, no ano de 1765 , que se começou a utilizar o adjetivo vernacular na forma latina vernaculus cujo sentido é o do que é próprio de um país, aquilo que é nativo.

No século XIX, precisamente no ano de 1823, os termos vernáculo e vernacular passaram a ter o mesmo sentido, ou seja, referiam-se a uma língua espontânea falada em

\footnotetext{
2 "Vernacular moderno? Por uma compreensão da noção de arquitetura e de seus laços com a modernidade arquitetural"
} 
determinado lugar e, nesse sentido, foram transformados no antônimo de Veicular, termo mais amplo e direcionado à comunicação entre grupos e de línguas diferentes. Foi também na mesma época que a ciência se apropriou do termo para nomear plantas e animais em oposição aos nomes latinos. Logo no início do século XX (1907) o adjetivo vernacular é substantivado pela Linguística para designar a língua vernacular.

Ao realizar longo percurso bibliográfico em busca da etimologia do termo vernacular na língua francesa, Bisson (2007) chega a uma conclusão interessante. Ao colocar em ordem as palavras utilizadas para definir o vernacular com as expressões latinas que lhe são antecedentes, ela lista as seguintes: escravos, nativo, país, familiar, lugar, vulgar, espontânea, nacional, profano, étnico. Por outro lado, ao verificar seu antônimo surgem as palavras: latim, veicular e sagrado.

Portanto, a primeira e interessante conclusão a qual se chega é a de que, na língua francesa, o termo vernacular não se refere a um prédio ou a uma construção, ou melhor, o vernacular ficou restrito a noções conceituais ou referente à língua e jamais a objetos físicos. A segunda e também interessante conclusão está relacionada ao espaço físico. Por exemplo, quando a autora observa palavras que identificam características mais precisas, ela constata que o vernacular está ligado a um lugar, a um ambiente, a exemplos de escravos, nacional e étnico ou a pessoas como as palavras escravo, nativo, familiar, vulgar. O vernacular está relacionado também a uma distinção como escravos, familiar, espontâneo, vulgar, profano. O termo veicular aparece como antônimo e está ligado e um tipo de organização e à difusão. Portanto, ela mostra como a língua é dinâmica.

Se o vernacular tem o seu antônimo, o veicular, como relacioná-los? A ideia de veicular, segundo as pesquisas de Bisson (2007), admite um amplo conjunto não necessariamente circunscrito a somente um ambiente físico. A definição de veicular ocorre desde 1823 e designa a língua do comércio, do mercado e cuja origem vem da Roma antiga. Não estava restrita somente à língua, representava também o Estado, o controle e a organização. Da mesma forma como vernacular, veicular também se refere à difusão e à cultura, por isso pode-se imputar aos dois certos graus de funcionalismo, mas é na escala onde são diferenciados, afirma ela.

Como está interessada no vernacular no contexto arquitetural, Bisson (2007), com esse amplo levantamento, certifica-se das razões pelas quais o termo resta intuitivo ou mesmo popular para qualificar uma construção na história da Arquitetura, quando estudiosos da

\begin{tabular}{llr}
\hline Soares e Aragão, 2021 & ISSN 0104-5490
\end{tabular}


língua francesa utilizam adjetivos específicos como menor ou regional no sentido de denotar valores comuns aos do vernacular pertencendo a um lugar ou tradição cultural.

De forma a surpreender, quando Bisson (2007) busca na literatura inglesa o significado de vernacular, aquela (a literatura inglesa) tem seu suporte na história da arquitetura e é nela que a expressão aparece mais forte. São nas obras britânicas que ela encontra a ligação entre a Arquitetura e o termo vernacular. Por exemplo, nessas obras o vernacular é descrito como casas de pessoas simples de uma determinada região. Em um dos principais dicionários ingleses, o Oxford, encontram-se dois significados ligados diretamente à arquitetura.

A Historiadora, em sua pesquisa, diz que a palavra aparece desde 1601 quando indica que se trata da língua nativa de um lugar e de um país. No entanto, o termo foi transportado para a arquitetura em 1857, sendo o primeiro significado podendo ter sido levado para o domínio das artes, mais particularmente para caracterizar a arquitetura doméstica, comum e própria de um país. O segundo significado se refere especificamente ao estilo arquitetural.

\section{E A GEOGRAFIA MAIS RECENTE, O QUE ELA TEM A ACRESCENTAR E A CONTRIBUIR? COM A PALAVRA, A GEÓGRAFA BÉATRICE COLLIGNON}

\footnotetext{
O que se sabe dos saberes geográficos vernaculares? Se parece oportuno colocar a questão é porque esses saberes são hoje reconhecidos em Geografia, mas continuam mal definidos. Procuram-se ainda desenhar seus contornos, ainda que geógrafos cada vez mais numerosos os integrem em suas análises sem, no entanto, os colocarem no coração de suas abordagens. (COLLIGNON, 2005, p. 322).
}

Até aqui vimos à etimologia da palavra vernacular comportando duas singularidades. A primeira, na língua francesa, quando o termo originalmente não se refere ao construído restringindo-se aos aspectos conceituais da linguagem. E a segunda singularidade, proveniente da língua inglesa, quando o termo é definido pelo aspecto físico da arquitetura.

Vimos também que, quando o geógrafo Raffestin (1978) vai refletir sobre a língua como poder, ele se apropria dos termos "vernacular" e "veicular" abrindo outros caminhos a serem explorados em Geografia. Então se faz necessário determinar como os geógrafos mais atuais ou mais recentes veem o "saber vernacular" e o "saber veicular" ou precisamente a "geografia vernacular" e a "geografia veicular" como paradigmas em Geografia. Este pequeno detalhe será muito esclarecedor para nossa proposta. Ele será o divisor de águas para 
sua compreensão, ou seja, como a Geografia define o vernacular e o veicular como saberes geográficos para além da Linguística e da Arquitetura e se isso ocorre. Portanto, como os novos geógrafos exploram os saberes vernacular e veicular e pontuam sua importância?

Béatrice Collignon (2005; 2014), no artigo intitulado "Que sait-on des savoirs géographiques vernaculaires? ${ }^{3}$ (What do we know about vernacular geographic knowledges)”, publicado no Boletim da Associação dos Geógrafos Franceses no ano de 2005, realiza um pequeno apanhado histórico e chama a atenção pelo fato de que, por muito tempo, os saberes vernaculares foram ignorados pela Geografia. Neste sentido, os conhecimentos elaborados sem a presença da ciência não eram reconhecidos como verdadeiros e impedidos de se questionar e foram denominados de "saberes invisíveis". Apesar das pesquisas de campo recolherem dados dos "informadores" estes não eram, contraditoriamente, reconhecidos como possuidores de um saber geral. Somente a partir do intervalo dos anos 1996 e 1998 é que se começou a observar o aumento de interesse por esses saberes, observando-se três principais perspectivas.

A primeira esteve sob influência da sociologia e, principalmente, através das pesquisas de Bruno Latour, a epistemologia da Geografia começou a se voltar para as relações existentes entre o saber erudito, ou seja, acadêmico e universitário e os saberes não eruditos, dos quais o saber erudito se nutre e integra, ou pelo menos em parte, acrescenta. Ela considera esse momento como não só de ruptura, de diferença de natureza entre os dois tipos de saberes, mas também em termos de continuidade.

Além disso, os estudos sobre representações em Geografia foram importantes para esta questão, pois a geografia acadêmica começou a ser vista não como um discurso exclusivo e exaustivo sobre o mundo. Outros saberes e não apenas os eruditos começaram a ter importância. Saberes geográficos outrora ignorados foram colocados em seu grau de importância. Até aí os conhecimentos humanos que não eram de interesse geográfico ficavam a cargo da antropologia.

Por último tem-se a integração de diferentes atores, seus territórios e ambientes, tendo como corolário suas representações cada vez mais importantes e reconhecidas como saberes geográficos. A geografia começou a reconhecer esses saberes como também começou

\footnotetext{
3 "O que se sabe dos saberes vernaculares?"

Soares e Aragão, $2021 \quad$ ISSN 0104-5490 8
} 
a criar meios para compreendê-los. Ao analisá-los, a geografia produziu meios para compreender as decisões dos diversos atores como também a dinâmica de seus territórios.

Estudiosa da temática e observando a necessidade de aprofundamento e de desenvolvimento de uma definição para a questão, Collignon (2005; 2014) propõe-se a realizar tal tarefa. Ela põe em questão inicialmente o próprio sentido de "saber" debruçandose sobre definições que considera as mais correntes e chega à seguinte conclusão: “[...] eu o defino como aquilo que dá sentido a uma situação ou a um evento pela mobilização de uma série de unidades de informações possuídas por aquele (aquela) que implementa este saber. $\mathrm{O}$ saber é assim uma harmonização interna das unidades de informações e sua atuação é um movimento". (COLLIGNON, 2005, p. 323). Finaliza afirmando que o saber é, portanto, um ato.

No que tange aos saberes eruditos ou científicos, a experiência, da mesma forma, tem papel fundamental nos saberes vernaculares, só que estes últimos não estão assentados em premissas analíticas. Por exemplo, se há uma multiplicidade de experiências nos saberes vernaculares, não se trata de testar todas as configurações possíveis, contanto não têm elas uma verificação sistemática. Portanto, e aqui aparece uma reflexão central dos saberes vernaculares, é a de que sua validade é dependente da coerência do conjunto e de sua eficácia, ao contrário dos saberes veiculares os quais dependem da exatidão de cada uma das unidades de informação. Principalmente quando aos saberes estão incorporados emoções e sonhos. Uma das características dos saberes vernaculares é a de que são pouco formalizados e, por isso, de teorização não muito acessível. Outra característica associada à primeira é o limite ao qual estão inscritos, pois não ultrapassam o exterior do grupo. Ao contrário, os saberes veiculares são discursivos, inscritos em modelos teóricos preocupados pela objetivação de uma realidade e comunicados fora do contexto. São essas as qualidades diferenciadoras que a geógrafa considera do significado de "saberes vernaculares" e o seu oposto, os "saberes veiculares".

Em contexto historiográfico a autora cita os trabalhos das etnociências realizados nos anos de 1950, trazendo para o debate a obra de Claude Lévy-Strauss intitulada de "La pensée sauvage". Nessa obra, diz ela, Lévy-Strauss mostrou que os saberes vernaculares são, na verdade, construções intelectuais impossíveis de serem reduzidas a uma prática fundada na experiência empírica. Ela mesma, em pesquisa sobre os povos Inuit e suas geografias, chegou à conclusão de que eles elaboram suas geografias vernaculares em movimentado conjunto de 
unidades de informação de tipos diversos advindos da experiência, das razões abstratas, por exemplo, da Geometria, da Física, da Biologia e assim por diante, como também estabelecendo reflexões de ordem filosófica, da espiritualidade tanto individual quanto coletiva, de crenças, sonhos e emoções. Para ela, todo esse conjunto constrói os saberes vernaculares dos Inuit. Collignon (2005, p. 325) formula, então, uma das mais pertinentes e completas reflexões sobre saberes geográficos vernaculares e as coloca frente ao saber erudito ou ao saber geográfico veicular:

\begin{abstract}
Os saberes geográficos vernaculares são, dessa forma, um envolvimento de todos os sentidos, que os fundem em uma experiência ontológica do espaço e do meio. Eles são necessariamente subjetivos e contextualizados, e só podem ser senão plurais. Se se pode verificar características comuns em todo saber geográfico vernacular, os conteúdos são sempre diferentes, como as culturas das quais são expressão. Em contrapartida, há somente um saber geográfico erudito, graças notadamente à objetivação que funda e legitima sua pretensão em direção a certa universalidade. (COLLIGNON 2005, p. 325).
\end{abstract}

Retomando o resumo histórico baseado em diversos autores e em si mesma, Collignon (2005) esclarece que somente com a ascensão do pós-estruturalismo nos anos 1980, quando a pesquisa antropológica abandona o estudo dos sistemas de classificações, ocorre a transferência do estudo das etnociências para um campo mais amplo, o dos "saberes autóctones", também chamados de "saberes nativos" e mesmo "saberes tradicionais" ou ainda "saberes ecológicos tradicionais", na medida em que se tratavam de caçadores-coletores. $\mathrm{Na}$ mesma época os etnólogos e especialistas de outras paragens se voltam a um passado próximo esquecido, mostra ela, e esse novo interesse se traduz no reconhecimento dos "saberes populares" ou "tradicionais".

A pesquisadora também esclarece as relações problemáticas existentes entre os saberes geográficos e outros saberes como as etnociências apontando a falta de afinidade dos antropólogos com os objetos da Geografia, a exemplo das interfaces homem/meio, espaço e território. No entanto, pode-se aqui ler a ausência de mudanças conceituais bem estabelecidas entre as duas disciplinas.

Dentre outros geógrafos inseridos nessa mudança de pensamento sobre saberes geográficos é citado o geógrafo Eric Dardel e sua proposta de 1952, assentada na lógica fenomenológica, ou seja, o ser como "ser geográfico" e a experiência geográfica como ontologia. No entanto, esclarece, a obra foi menos influenciada pelos fenomenólogos do que 
pelos trabalhos de Michel Foucault e Gilles Deluze, assim como pela Sociologia das ciências, como desenvolveram Bruno Latour e Michel Calenge.

Para ela, poderia se esperar a construção de relações mais fortes entre pesquisadores sobre geografias vernaculares e ciências cognitivas, mas não é o caso. A razão ocorre por que as ciências cognitivas estiveram fortemente marcadas pelos estudos concernentes às competências espaciais dos indivíduos e suas cartas mentais, com abordagens muito analíticas e positivistas, com sua conexão cada vez mais forte à neurociência resultando em um distanciamento do projeto das Ciências Sociais contemporâneas.

Outra coisa a ser bem pensada e como determinante são as questões metodológicas e de método em si. Para isso, coloca o pertinente questionamento integral: como apreender saberes não formalizados, fortemente marcados pela personalidade de cada indivíduo que os possui e os reconstrói à sua conveniência? Destaca a problemática de que os geógrafos não têm desenvolvido competências nesse domínio e aponta uma saída.

[...] ainda que a geografia social se volte cada vez mais para levantamentos tipo qualitativo, privilegiando entrevistas e os relatos, é importante oferecer ferramentas úteis para decodificar os discursos recolhidos. Insistir sobre os saberes geográficos vernaculares é também oferecer os meios de considerar as palavras dadas como expressão de um todo que faz sentido, não como elementos de informações isoladas que o pesquisador pode manipular à sua conveniência como se tem feito há muito tempo. (COLLIGNON, 2005, p. 328).

No que se refere ao método, destaca como oportuno cruzar duas práticas que considera clássicas na Geografia, ou seja, a pesquisa de campo juntamente com a análise de discurso. Pela razão de serem saberes pouco formalizados e geralmente não discursivos, fazse necessária a observação a qual permite inserir o saber em atos; essa conduta é considerada indispensável. A observação deve estar associada a uma análise refinada dos discursos e isso em todas as ordens, como imagens, textos, relatos, entrevistas, o que incumbirá o pesquisador de realizar sua desconstrução. Para finalizar, sugere duas ferramentas as quais considera mais prometedoras, quais sejam a da escola internacionalista da Linguística e da etnometodologia. 


\section{E O GEÓGRAFO JÈrôME MONNET, O QUE TEM A DIZER SOBRE ESTES CONHECIMENTOS?}

As ciências cognitivas, para as quais chama atenção Collignon (2005) como trato metodológico questionável é o caminho trilhado por outro geógrafo chamado Jèrôme Monnet (1999a; 1999b) para justificar seus estudos sobre as problemáticas do vernacular. Como possíveis de serem aplicadas, ele traz para a discussão o que chama de dualidades contraditórias. As dualidades contraditórias se referem aos estudos do "real" que, com a ciência, se tornou o mais abstrato possível, levantando como exemplos as cartografias temáticas e as massas estatísticas; enquanto a realidade mais concreta, ou seja, a existência material dos indivíduos é considerada pertinente ao seu imaginário. Surge aí o contraditório: o concreto se torna subjetivo enquanto que o abstrato se torna objetivo. Ele direciona uma saída.

\footnotetext{
Para sair dessas realidades contraditórias, faz-se necessário ter atenção sobre as relações, sobre os processos que estabelecem essas relações. Assim, uma vez que as representações são representadas (se posso dizer) como produtos, é preciso retornar às condições de sua produção. As Ciências cognitivas e a Psicologia da percepção estudam o conjunto dos processos pelos quais o sujeito põe em relação sua realidade interior e sua realidade exterior. É preciso nelas se inspirar para trabalhar na escala geográfica, isto é, na articulação dos espaços (ou meios) individuais e coletivos. (MONNET, 1999a, p. 96).
}

Para isso, afirma que é preciso pensar "em circuito" - retroatividade- no sentido de levar as Ciências cognitivas considerando-as um circuito fechado, ou melhor, pensar o circuito "representação-ação". Só que, quando ele traz uma citação de Jean Decety afirmando que a ação representa a noção de plano para um determinado objetivo e a noção de representação como central nos modelos de controle da ação, ele diz que esse ciclo não fecha quando se leva para uma escala geográfica. Primeiro, pela razão de o sujeito não deixar de existir e, segundo ele, os geógrafos às vezes o esquecem como escala, ainda que pertença a um número potencialmente infinito de sujeitos coletivos. Por isso, o estudioso apresenta as três formas de interações do indivíduo com o "meio" e, se é uma interação, ela ocorre ao mesmo tempo.

De início, essas interações ocorrem com um ambiente sensorial pela sua individualidade. Depois, com um número sempre mutante em relação a outros sujeitos individuais. Há aqui as interações sensorial e interpretativa, porém jamais serão exatamente similares, levando em conta suas diferenças físicas e mentais e jamais iguais no mesmo

\begin{tabular}{lll}
\hline Soares e Aragão, 2021 & ISSN 0104-5490
\end{tabular}


espaço-tempo de um outro. Diz o autor que é o que se percebe, pelo menos, na teoria euclidiana. Por fim, as interações ocorrem entre o indivíduo e cada uma das coletividades a que pertence, próprias a seu meio. Havendo interações específicas entre indivíduo e cada meio com o qual essas coletividades têm interações.

Monnet (1999a) chama atenção para a potência dessas interações, considerando-as fortes ou tênues observando: sua frequência temporal, o problema, a intensidade do fenômeno e assim por diante. Aponta também a questão das hierarquias e sua complexidade operadas em diferentes critérios. Essas são suas reflexões de concepção da realidade e sua complexidade. E para abordar essa realidade complexa ele constrói seu postulado conceitual "interpretaçãoordenamento" como desempenho geográfico por excelência.

É a partir dessas reflexões e da questão da urbanidade como modo de socialização/espacialização específica da cidade que ele chega à noção de vernacular e sua relação com o espaço e o saber geográfico. Dessa forma, ele apresenta a problemática do vernacular e sua interação com o veicular. Para tanto, traz a categoria "sujeito" para suas reflexões. Mas o sujeito, aquele que evoca a consciência, ou melhor dizendo, o sujeito que tem uma certa soberania mesmo na subjugação. Esse sujeito que está presente em toda ação. É refletindo sobre esse sujeito que ele chega ao que entende de geografia vernacular.

\footnotetext{
É seguindo esta ideia, que toda ação sobre o mundo é ao mesmo tempo produtora e produto do saber do sujeito sobre o mundo, que parece importante estudar os geógrafos "vernaculares". Chamo assim as formas de organização do espaço resultante da multiplicidade das retrodeterminações "representação-ação" e os saberes que correspondem a uma multiplicidade de urbanidades e outras espacialidades. Esta geografia vernacular é ao mesmo tempo uma geografia erudita, um saber e objeto desse saber. (MONNET, 1999a, p.107).
}

A partir desta reflexão ele destaca duas fontes de inspiração para a noção de vernacular. A primeira se refere ao domínio da comunicação onde se opõem a língua vernacular, ou seja, a que é falada só localmente, por um grupo local e, a língua veicular, a que tem um alcance mais amplo, a que serve de comunicação de grupos à longa distância. Monnet (1999a) justifica esse dualismo afirmando ser típico de uma civilização que sempre quis resolver o problema de comunicação impondo uma língua comum, a exemplo do inglês técnico atual. Outras línguas também tiveram seu apogeu de dominação, como o latim e o francês diplomático do século XVIII. 
A outra noção de vernacular se refere à Arquitetura. Esta difere da primeira enquanto não mais evoca um instrumento de comunicação, tratando-se de um objeto produzido por um saber não necessariamente acadêmico e, nesse sentido, não comunicável em língua erudita veicular. Para Monnet (1999a), quando se fala de arquitetura vernacular a modo dos especialistas do patrimônio ou arqueólogos, remete-se a uma forma de hierarquização entre as diferentes formas de codificação do saber e suas produções materiais. Dessas explanações, ele chega à diferenciação do que sejam uma "geografia vernacular" e uma "geografia veicular".

\begin{abstract}
Interessar-se pela geografia vernacular implica em considerar todas essas acepções do termo. Julgo que se pode assimilar a geografia acadêmica (minha disciplina) a um saber veicular, naquilo em que ela é codificada de maneira a permitir sua comunicação entre grupos e à distância (isso não quer dizer que ela seja acessível a um grande número; é sua dimensão elitista). Em oposição, chamo geografia vernacular o saber do espaço/sobre o espaço desenvolvido por todos, nos termos em que são marginalmente comunicáveis (MONNET, 1999a, p. 108).
\end{abstract}

Vemos que, para ele, "geografia veicular" ou "geografia acadêmica" e "geografia vernacular" estão no mesmo campo de entendimento; o que vai diferenciá-las é o campo de ação, o limite de alcance. Mas faz-se preciso exemplificar para tornar os termos mais inteligíveis. Para ele, todos os indivíduos possuem uma geografia nata do lugar onde vivem, adquirida por ser locus de sua experiência íntima. Nisso eles podem se orientar corretamente através do seu subconsciente. Só que, quando querem transmitir a outro sujeito os elementos desse conhecimento do espaço, ela, a transmissão, ocorre de forma não precisa, é "empobrecida". Ao menos de uma porção importante que foi demandada. De outro lado, a deficiência ocorre porque uma pequena parte da experiência e do conhecimento do espaço foi conceituada de forma a ser comunicável. Dessa forma, o que vai diferenciar a geografia vernacular da geografia erudita ou acadêmica é que a geografia vernacular não está estruturada ao ponto de se tornar geografia veicular. Monnet (1999a) chama atenção para outro detalhe importante quando se refere à abstração do espaço.

[...] assim como o objeto da geografia acadêmica é a organização do espaço em um certo nível de abstração (o espaço, a cidade, sendo estes abstrações), uma geografia vernacular concreta corresponde a um saber vernacular: trata-se do espaço produzido no quadro desses saberes, o espaço dos usos e das imagens, das práticas e das representações multiplicadas pelo número de usuários. [...] há uma questão científica identificada há algum tempo em se ocupar desses saberes e desses espaços vernaculares: tudo o que não era considerado racional e então da geografia 
acadêmica, ao lado de outras disciplinas científicas, exigiu esforços para sua compreensão com uma racionalidade própria (o setor econômico informal, as migrações para as grandes cidades, a violência contra os serviços públicos, etc.). (MONNET, 1999a, p. 109).

A proposta de Monnet (1999a; 1999b) para que se resolva esse entrave é a de que a geografia veicular interaja com a geografia vernacular. Por exemplo, a geografia veicular poderia trabalhar em conjunto a geografia vernacular da insegurança, assim como a possibilidade de se pesquisar sobre uma geografia vernacular da noite, das palmeiras, das lixeiras no sentido de como as pesquisas poderão ajudar na compreensão dos usuários do espaço, ou como eles o interpretam, qualificam e os constroem.

\section{CONSIDERAÇÕES FINAIS}

As considerações finais da proposta deste artigo apresentam dois momentos: primeiro reforça a importância desses dois saberes no âmbito da ciência geográfica no sentido em que merecem olhares mais agudos dos pesquisadores acadêmicos em geografia já que estão interligados em nossas vidas comuns e de ofício, ou seja, na longa vida escolar. Eles andam juntos, estão inseparáveis porquanto somos habituais, e nos tornamos eruditos sem perdermos nossas essências de pessoas comuns.

O segundo momento está relacionado ao eruditismo propriamente dito, ou seja, ao quadro de pesquisas em geografia nas universidades onde os autores do artigo atuam, sendo o LEGEC (Laboratório de Estudos em Geografia Cultural) na Universidade Estadual do Ceará UECE, coordenado pelo professor Dr. Otávio José Lemos Costa, inspirador do artigo e, a Universidade Federal do Ceará - UFC, nos estudos coordenados pelos professores Christian Dennys Monteiro de Oliveira e Tiago Viera Cavalcante por intermédio do LEGES (Laboratório de Estudos Geoeducacionais e Espaços Simbólicos) onde o campo interdisciplinar direciona a imersão das pesquisas a estes dois saberes em diversas abordagens desde a poesia, a geografia e a literatura, passando pelo imaginário, o geossimbolismo e a questão patrimonial.

Neste sentido, a rede OPPALA - Observatório de Paisagens Patrimoniais e Artes Latino Americano é exemplo singular da parceria UECE, UFRN - Universidade Federal do Rio Grande do Norte - e UFC. O observatório tem como objetivo enriquecer as dialógicas abordagens culturais na Geografia e, assim, direcionar olhares atentos sobre patrimônios vivos, 
materiais e imateriais latino-americanos, tanto suas representações artísticas quanto tecnológicas das diversas identidades de nosso continente, ou seja, sua complexidade paisagística. O vernacular e o veicular - mesmo que não utilizando diretamente estas expressões - compõem o arcabouço do pensamento desses professores pesquisadores que atuam como disseminadores dessas redes de conhecimentos, inovando na pesquisa geográfica brasileira e latino-americana.

\section{REFERÊNCIAS}

BISSON, Marie-Franc. Vernaculaire moderne? Vers une compréhension de la notion d'architecture vernaculaire et des ses liens avec la modernité architecturale. Mémoire présanté comme exigence partielle de lamaîtrise em étude des arts. Universitédu Québec à Montreal, 2007. Disponível em: <

archipel.uqam.ca/849/1/M10082.pdf>. Acesso em: 06 mai. 2019. Pp. 1-160.

COLLIGNON, Béatrice. Que sait-on des savoirs géographiques vernaculaires? (What do we know about vernacular geographic knowledges). In: Bulletin de l'Association de géographes français, 82e année, 2005-3 (septembre). La géographie économique au début du XXIe siècle: agglomération et dispersion / Géographie vernaculaire. pp. 321-331. Disponível em: < https://www.persee.fr/doc/bagf_0004-5322_2005_num_82_3_2467>. Acesso em: 16 mai.

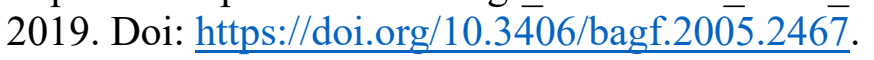

COLLIGNON, Béatrice. Savoirs vernaculaires. In: Hypergeo, encyclopédie électronique, 2014. Disponível em: <http:/www.hypergeo.eu/spip.php?article298\#>. Acesso em: 12 mai. 2019. Pp. 1-3.

MONNET, Jérôme. Images de l'espace à Los Angeles: éléments de géographie cognitive et vernaculaire. In: Communication au Colloque de l'Institut universitaire de France. "Espace(s)", $\quad$ Toulouse, $1999 . \quad$ P. 1-28. Disponível em: <http://webast.ast.obsmip.fr/people/rieutord/IUF_conflactes.html>.Acesso em: 19 nov. 2010.

MONNET, Jérôme. Interpréter et aménager: eléments d'une géographie de la relation au monde. Dossier de candidacture à l'habilitation à diriger les recherches. Paris, 1999. In: Halshs (Hyper Article en Ligne - Sciences de l'Homme et de la Société)-00006770, version 1 - 6 Dec 2005. Disponível em: <http://hal.inria.fr/docs/00/05/08/13/PDF/Monnet-HDRvol1.pdf>. Acesso em: 22 mar. 2012.

RAFFESTIN, Claude. La langue comme ressource: pour une analyse économique des langues vernaculaires et vèhiculaires. In: Cahiers de Gégraphie du Québec, Vol. 22, no. 56, septembre 1978, pp. 279-286. Disponível em em: <

https://www.erudit.org/fr/revues/cgq/1978-v22.../021396ar.pdf>. Acesso em: 08 mai. 2019. DOI : https://doi.org/10.7202/021396ar. 
RAFFESTIN, Claude. Langue et territoire. Autour de la géographie culturelle. In: WALTY Samuel; WERLEN Benno (Ed.). Kulturen und Raum: theoretische Ansätze und empirische Kulturforschung in Indonesien: Festschrift für Professor Albert Leemann. Zurich: Rüegger, 1995. p. 87-104. (Konkrete Fremde; 10). Disponível em: $<$ https://archiveouverte.unige.ch/unige:4451>. Acesso em: 14 mai.2019. 